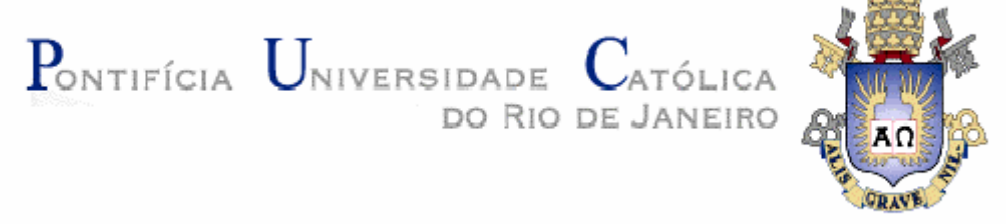

Rita de Cássia Souza Leal

Usos e Apropriações dos "sem-tela" na rede:

Um estudo comparativo sobre as condições de acesso dos jovens à Internet no Brasil e na Itália

Tese apresentada ao Programa de PósGraduação em Educação do Departamento de Educação da PUC-Rio como parte dos requisitos parciais para obtenção do título de Doutor em Educação.

Orientador: Profa Maria Apparecida C. Mamede-Neves

Rio de Janeiro

Fevereiro de 2010 
Rita de Cássia Souza Leal

\section{Usos e Apropriações dos "sem-tela" na rede: \\ Um estudo comparativo sobre as condições de acesso dos jovens à Internet no Brasil e na Itália}

Tese apresentada como requisito parcial para obtenção do título de Doutor pelo Programa de Pós-Graduação em Educação do Departamento de Educação do Centro de Teologia e Ciências Humanas da PUC-Rio. Aprovada pela Comissão Examinadora abaixo assinada.

Prof $^{\text {a }}$ Maria Apparecida C. Mamede-Neves

Orientadora

Departamento de Educação - PUC-Rio

Prof $^{\text {a }}$ Stella Maria Peixoto de Azevedo Pedrosa

Departamento de Educação - PUC-Rio

Prof $^{a}$. Maria Cristina Monteiro Pereira Carvalho Departamento de Educação - PUC-Rio

Prof. Píer Cesare Rivoltella Università Cattolica del Sacro Cuore de Milão

Profa. Monique Mendes Franco

FFP/ UERJ

Prof. Paulo Fernando C. de Andrade Coordenador Setorial do Centro de Teologia e Ciências Humanas

Rio de Janeiro, 5 de fevereiro de 2010. 
Todos os direitos reservados. É proibida a reprodução total ou parcial do trabalho sem autorização da universidade, da autora e do orientador.

\section{Rita de Cássia Souza Leal}

Rita de Cássia Souza Leal graduou-se em Comunicação Social na Sociedade Educacional da Cidade - UNIVERCIDADE (1993), e obteve uma segunda graduação em Licenciatura em Pedagogia na Universidade Estácio de Sá - UNESA (2004). Cursou a Pósgraduação em Letras, com Especialização em Literatura Brasileira (1995), na Pontifícia Universidade Católica do Rio de Janeiro - PUC - Rio. Como bolsista da CAPES concluiu o Mestrado em Comunicação e Cultura, na área de Novas Tecnologias e Estética na Universidade Federal do Rio de Janeiro - UFRJ em (2006), com a dissertação "Câmeras de Vigilância: as novas tecnologias na governamentalidade contemporânea”. No Doutorado em Educação na Pontifícia Universidade Católica do Rio de Janeiro - PUC - RIO, apresentou a tese "Usos $e$ apropriações dos "sem-tela" na rede: um estudo comparativo sobre as condições de acesso dos jovens à Internet no Brasil e na Itália”.(2010). Durante o Doutorado foi bolsista CAPES, sendo contemplada com uma bolsa PDEE de estágio sanduíche de seis meses no exterior, desenvolvido junto a Università Cattolica Del Sacro Cuore di Milano, sob a orientação do Professor Píer Cesare Rivoltella. No segundo ano do Doutorado passou a ser bolsista da FAPERJ, com a Bolsa Aluno Nota Dez.

Ficha Catalográfica

Leal, Rita de Cássia Souza

Usos e apropriações dos "sem tela" na rede : um estudo comparativo sobre as condições de acesso dos jovens à internet no Brasil e na Itália / Rita de Cássia Souza Leal ; orientadora: Maria Apparecida C. Mamede-Neves. - 2010. 268 f.: il. ; $30 \mathrm{~cm}$

Tese (Doutorado em Educação)-Pontifícia Universidade Católica do Rio de Janeiro, Rio de Janeiro, 2010. Inclui bibliografia

1. Educação - Teses. 2. Juventude. 3. Internet. 4. Divisão digital. 5. Acesso. I. Mamede-Neves, Maria Apparecida C.. II. Pontifícia Universidade Católica do Rio de Janeiro. Departamento de Educação. III. Título. 


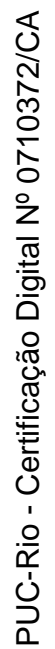

Aos meus filhos Rafael e Eduardo, porque os anjos existem. 


\section{Agradecimentos}

Agradeço a força maior que nos dá coragem, esperança e nos faz acreditar na possibilidade de realizarmos o impossível.

Agradeço a humana guerreira, companheira de jornada e minha super orientadora Maria Apparecida Mamede-Neves, que me apoiou e me incentivou nos momentos mais difíceis desse percurso. Cida dedico a você toda a minha admiração e respeito. Esteja certa de que, sem a sua companhia essa tese não existiria.

Ao Professor Rivoltella, que me acolheu na Universidade Católica de Milão, me apoiando, orientando e fornecendo o suporte necessário para a realização desse trabalho.

A amiga e companheira de varias horas Monique Franco, que segurou as pontas das minhas fraquezas nos momentos mais difíceis e sempre me disse que era possível.

Ao Milton, amigo e companheiro, que me deu forças e estimulou nas minhas escolhas dos caminhos e das trilhas que resultaram na minha chegada aqui.

A professora e coordenadora da pós-graduação Rosália Duarte, pelos ensinamentos e pelos momentos divididos, dos mais leves aos mais difíceis.

Aos amigos e companheiros do JER que me acompanharam, mesmo quando estava na Itália, contribuindo com textos e sugestões e que torceram por mim até quando tudo parecia não ser possível.

Ao corpo docente da PUC, pelas trocas e pelos ensinamentos, mas, acima de tudo, pela capacidade de compreender e ajudar aos alunos da Pós nas demandas mais difíceis e impensadas. É uma grande sorte ter a oportunidade de saber que podemos contar com o apoio de vocês.

Aos amigos e companheiros do CREMIT que me acolheram, me ajudaram nas etapas empíricas dessa tese e fizeram, algumas vezes, me sentir pertencente a uma ‘família italiana'. Em meio a essa família dedico um agradecimento muito 
especial à colega e companheira Magda Pischetola, pelas indicações e por compartilhar das minhas dúvidas e inquietações dividindo comigo o prazer e o sofrer do processo de construção desse trabalho.

Também um agradecimento carinhoso para a companheira e amiga Alessandra Carenzio, una persona troppo speciale, pelas suas contribuições e pela sua disponibilidade em ajudar.

Ao pessoal da secretaria do Departamento de Educação, em especial Geneci, Janaína e Neiva, que sempre me ajudaram e me acompanharam na luta dos processos burocráticos, mas com o carinho e a amizade dos que realmente se preocupam. Um obrigado especial a vocês.

A Jesus e a Gisele que foram peças fundamentais para a realização do trabalho empírico no Brasil, abrindo para mim as portas do universo até então pouco conhecido das LAN houses e que, ao fim, se tornaram meus grandes amigos de jogos e de tese.

As amigas Ilana e Kelly Russo pela cumplicidade e pelo companheirismo que tornou o percurso menos solitário.

Aos amigos e companheiros do curso de Doutorado, com quem muitas vezes dividi as dúvidas e as inseguranças, mas também os chopps e os risos, logo ali no planetário.

A Rubinho pela força e pela ajuda nos momentos mais difíceis dessa tese e principalmente pelo desespero que vi em seus olhos por achar que não podia contribuir mais. Engano seu, você me ajudou e muito!

A Monica Paes pelo carinho e amizade com que me acolheu e esquentou em meio ao frio italiano. Você é mesmo uma irmã, amiga!

A Antonio Bottino, un bravo maestro e um grande amigo.

Aos meus filhos pelo mutirão final e pelo amor que me dedicam. Vocês são tudo e muito mais!!

A todos os meus amigos que hoje sei são muitos, brasileiros e italianos, saibam que cada um, ao seu modo e possibilidade, tem um pouco de sua presença impressa nesse trabalho.

A CAPES pela concessão da bolsa de estudos aqui no Brasil e na Itália e a FAPERJ pela bolsa nota dez com a qual fui contemplada.

Enfim a todos os que, direta ou indiretamente, fizeram com que esse trabalho esteja hoje concretizado nesse texto que vocês estão lendo. O meu

Muito Obrigado! 


\section{Resumo}

Leal, Rita de Cássia Souza; Mamede-Neves, Maria Apparecida C. Usos e Apropriações dos "sem-telas" na rede: um estudo comparativo sobre as condições de acesso dos jovens à Internet no Brasil e na Itália. Rio de Janeiro, 2010. 268p. Tese de Doutorado - Departamento de Educação, Pontifícia Universidade Católica do Rio de Janeiro.

A tese apresenta um estudo comparativo entre o Brasil e a Itália, no que se refere aos usos e apropriações que os jovens da população de baixa renda ou com poucas oportunidades de acesso, fazem da e na Internet. Com base nos pressupostos metodológicos da pesquisa qualitativa, a investigação visa compreender as mudanças provocadas pela inserção da rede no cotidiano desses jovens, considerando duas realidades distintas. Assim, em diálogo contínuo com os teóricos que estudam o tema, a tese apresenta e analisa discursos oficiais e midiáticos, dados estatísticos sobre os usos das TIC’s nos dois países, além das falas de coordenadores, mentores e usuários. Na delimitação do campo empírico, a tese faz um recorte na realidade italiana, elegendo o projeto 'terza área' desenvolvido pelo Cremit - Centro de Pesquisa da Universidade Católica do Sagrado Coração de Milão em parceria com o Instituto Escolar Oriani Mazzini, voltado para a inclusão de estudantes com poucas oportunidades de acesso aos meios. Já no Brasil, o recorte recaí sobre as LAN houses, centros pagos de acesso à Internet, por meio das falas dos estudantes do Instituto de Educação Clélia Nanci, em São Gonçalo, Rio de Janeiro, todos na condição de usuários freqüentes das LANs, fenômeno que perpassa as diferentes classes sociais, mas são locais preferidos para o acesso à Internet entre a população menos favorecida. Nesse sentido, é introduzida a questão da desigualdade de acesso, da divisão digital, da construção da cidadania e da democracia, além do papel da educação nesse contexto. As contribuições significativas estão na reflexão crítica sobre a questão do acesso e nos questionamentos sobre a divisão digital, tanto no Brasil, quanto na Itália. Os resultados obtidos oferecem pistas para a articulação de projetos educativos que concebam a inclusão digital sob a ótica da inclusão social, posto que, como indicam os dados, uma não se realiza sem a outra.

\section{Palavras-chave:}

Juventude; internet; divisão digital; acesso; educação. 


\section{Abstract}

Leal, Rita de Cássia Souza; Mamede-Neves, Maria Apparecida C. (Advisor) Uses and appropriations of the "no-screen" in the network: a comparative study on the conditions of young people to the Internet in Brazil and Italy. Rio de Janeiro, 2010. 268p. PhD. Dissertation Departamento de Educação, Pontifícia Universidade Católica do Rio de Janeiro.

The thesis presents a comparative study between Brazil and Italy, with regard to Internet uses and appropriations referred to young people of low income or with limited access opportunities. Based on the methodological assumptions of qualitative research, the research aims to understand the changes caused by the impact of Internet in young people's of everyday life, considering two different realities. Thus, in continuous dialogue with theorists who study the subject, the thesis presents and analyzes media and official speeches, statistics on the uses of ICT in both countries, in addition to the testimonies of coordinators, mentors and users. In defining the empirical field, the thesis makes a cut in the Italian reality, choosing a project called 'terza area' developed by Cremit - Research Center of the University of the Sacred Heart of Milan in partnership with the School Oriani Mazzini, toward the inclusion students with few opportunities for media access. In Brazil, the clip falls on LAN Houses, shopping paid Internet access, through the speeches of the students of the Institute of Education Clelia Nanci in Niteroi, Rio de Janeiro, the same condition as frequent users of LANs, a phenomenon running through the different social classes, though remaining a preferred location for Internet access among the less favored population. In this sense, we introduce the issue of unequal access, digital divide, the construction of citizenship and democracy, and the role of education in this context. The significant contributions are in critical reflection on the issue of access and questions about the digital divide, both in Brazil and in Italy. The results provide clues to the articulation of educational programs that develop digital inclusion from the perspective of social inclusion, since, as indicated by the data, one does not take place without the other.

\section{Key-words:}

Youth; internet; digital divide; access; education. 


\section{Sumário}

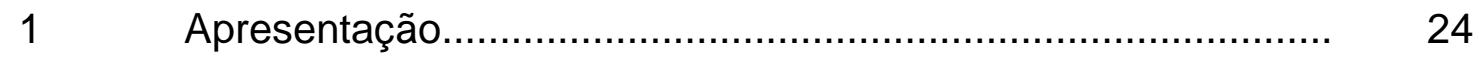

$2 \quad$ Quadro Teórico: um recorte …............................................... 34

$2.1 \quad$ Um pouco de história ……............................................... 35

2.2 Em tempos de 'Sociedade da Informação ................................ 40

2.3 Representações e culturas: novos olhares .............................. 47

$2.4 \quad$ Os jovens e a Internet ........................................................... 60

$2.5 \quad$ Novas experiências de tempo e espaço ..................................... 73

$3 \quad$ Escolhas metodológicas ........................................................ 84

3.1 Caminhos percorridos: rupturas e continuidades ……................. 86

3.2 Os atores da pesquisa ...................................................... 91

3.3 Os instrumentos: trilhas percorridas ……................................ 97

3.4 Procedimentos adotados ..................................................... 100

$4 \quad$ Educação, "e- democracia", "e-cidadania" ................................. 104

4.1 Educação: construção colaborativa ....................................... 104

4.2 "e- democracia": um projeto que se digitaliza ......................... 114

4.3 "e- cidadania": construindo a cidadania na era digital .............. 125 
5 "Digital divide": desigualdades de usos e acessos

5.1 Discutindo a divisão digital no mundo .................................. 137

5.2 Os jovens: acessos e usos no Brasil ...................................... 146

5.3 Os jovens: acessos e usos na Itália ................................ 159

5.4 LAN houses: uma possibilidade de inclusão no Brasil .............. 170

5.4.1 Discurso do presidente da ABCID .................................... 187

5.5 Projeto 'terza área' - um projeto de inclusão na Itália .............. 196

5.5.1 Discurso da coordenação do projeto ......................................... 205

5.6 Comparando duas realidades: o que dizem os jovens usuários 210 do Brasil e da Itália

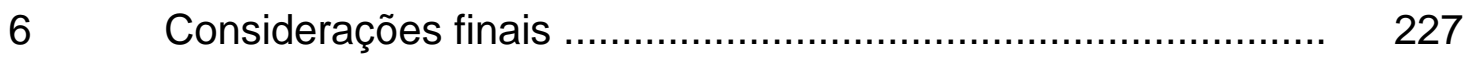

$7 \quad$ Referências Bibliográficas ......................................... 241

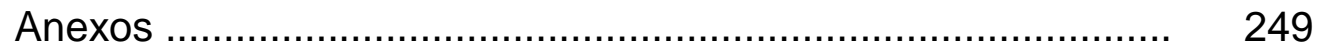

Anexo 01 - Site consultados ..................................... 250

Anexo 02 - Convênio Projeto 'terza área' (original em Italiano .. 251

Anexo 03 - Currículo e roteiro de entrevista com a coordenadora do Projeto 'terza area" na Itália ...................... 255

Anexo 04 - Roteiro de entrevista com o presidente da ABCID .. 256

Anexo 05 - Questionário aplicado entre os jovens estudantes no Brasil e na Itália - versões em português e italiano ............. 257

Anexo 06 - Os dez mandamentos das LAN Houses ................ 266

Anexo 07 - Princípios para a governança e uso da Internet ...... 267

Anexo 08 - Fotos do projeto 'terza area' - durante a aplicação dos questionários 


\section{Lista de Siglas, Significados e Abreviações}

ABCID

ACK

Acesso

Adware

ARP

ARPA

Assinatura Digital

Avatar

Backbone

Baixar

Banda Larga

Banner

BIT

Byte

Bitmap

Blog
Associação Brasileira de Centros de Inclusão Digital.

Resposta enviada de um computador receptor a um computador emissor para indicar o recebimento bemsucedido de informações.

Entrada em site ou entrar na própria Internet através de uma conexão.

Qualquer aplicativo no qual são exibidos banners de propaganda durante a execução do programa.

Protocolo de Conversão de Endereços na suíte TCP/ IP usado para converter um endereço (IP) de rede no seu endereço da camada de ligação.

Advanced Research and Projects Agency criada em 1969.

Assinatura eletrônica impossível de falsificar que autentica o remetente de uma mensagem e garante a integridade dessa mensagem.

Nome dado a representação gráfica do usuário no ambiente virtual.

O canal principal de uma rede de computadores, a qual todos os usuários e demais redes estão conectados.

O mesmo que download, ou seja, trazer para seu computador um programa, um texto ou uma imagem.

Tipo de conexão rápida pela Internet.

Publicidade na Internet, ou seja, são os anúncios comerciais ou institucionais.

Menor unidade de informação eletrônica. Um Bit é um algarismo (0 ou 1)

O Byte é uma unidade que permite medir a quantidade de informação e é, normalmente, o conjunto de oito bits.

Significa mapa de bits em inglês; são imagens que contém a descrição de cada pixel, em oposição aos gráficos vectoriais

Corruptela de weblog 
Browser

Buffer

BUG

Cache

Cavalo de Tróia

CDI

CGI

CHAT

Cibercafés

Cibercultura

Ciberspace

CMC

Comunidade virtual - $\mathrm{CV}$
Browser - mesmo que navegador são os programas utilizados para acessar as páginas de Internet. Exemplos: Internet Explorer, Netscape Navigator entre outros.

Usado para liberar o processador por se tratar de uma memória de uso rápido e imediato.

Um bug é um erro num programa (software) ou mesmo num equipamento (hardware) que provoca uma ação inesperada.

Parte da memória do computador ou do disco rígido que armazena dados freqüentemente requisitados, de modo a aumentar a rapidez de acessibilidade.

Um programa incorporado em um programa que, de outra forma, seria inofensivo, usado para atacar um local.

Comitê para Democratização da Informática

Comitê Gestor da Internet

Sala de bate-papo através de mensagens de textos em tempo real na Internet.

Bar ou café que oferece em seu espaço computadores para acesso à Internet.

É um termo utilizado na definição dos agenciamentos sociais das comunidades no espaço eletrônico virtual.

Denomina o espaço eletrônico onde as informações da Internet circulam.

Comunicação Mediada por Computador

Grupo de pessoas que possuem interesse em comum e que se reúnem através de ferramentas na Internet para realização de cooperação e trocas, independente do espaço geográfico em que se localizam fisicamente

CPA

Centro Público de Acesso

CPU

Unidade central de processamento. O termo é usado de forma coloquial para representar a "caixa" do computador, o gabinete.

Cracker

Um hacker que não respeita os computadores que invade. A palavra é derivada de Criminal Hacker (Hacker Criminoso).

Centro de pesquisa em Mídia, Educação e Novas Tecnologias, vinculado à Universidade Católica do Sagrado Coração de Milão (UCSC), Itália. 
CS

Dial-up

Digital Divide

Domain

Download

Email

Emoticons

Endereço IP

Facebook

Filtros

Firewall

Fórum

Freeware

Game

Gateways

Hacker
Counter Strike: game de tiro em primeira pessoa.

Tecnologia de conexão com a Internet caracterizada por utilizar um modem e a linha telefônica, também conhecida como "conexão discada".

Divisória digital, brecha digital e, mais comumente utilizado para se referir à exclusão digital.

( Domínio ) - nome que vem após a @ dos endereços de email. Designa também o próprio endereço de um site.

Mesmo que baixar ou transferir dados de uma página da Internet para seu computador.

Correio eletrônico. O endereço pelo qual você envia e recebe mensagens.

Ícones que utilizam caracteres do teclado a fim de, quando visualizados lateralmente, imitar feições faciais para expressar sentimentos e ações: sorrindo :-), triste :-(, mostrando a língua :-P, chorando ;,-( etc. Têm o propósito de explicitar emoções nas comunicações puramente textuais.

Endereço numérico de um site, formado por um grupo de números separados por pontos, ex. 173.341.123. 4.

É um website de relacionamento social lançado em 2004, por Mark Zuckerberg, um ex-estudante de Harvard.

Um firewall de host que registra e filtra o acesso dos clientes aos aplicativos do servidor. Um dispositivo conectado em rede que procura informações para determinar se eles devem ser bloqueados ou liberados.

Um ou mais filtros e gateways de pacotes que blindam as redes confiáveis "internas" das redes não-confiáveis "externas", tais como a Internet.

O mesmo que grupo de discussão na rede.

Programas de uso livre e gratuito pela Internet.

É um jogo eletrônico no qual o jogador interage com imagens enviadas a um dispositivo que as exibe.

Porta de ligação, é uma máquina intermediária geralmente destinada a interligar redes, separar domínios de colisão, ou mesmo traduzir protocolos.

Pessoa que obtém acesso ilegalmente ao seu computador. 
Hardware

Hiperlink

Homepage

Host

HTML

HTTP

IBASE

IBGE

IBOPE

ID

IDH

Interatividade

Internet

Intranet

IP

Istat

Java

JER

JPEG

LAN
São os dispositivos "duros" de um computador, tais como chips, placas, fios, cabos, fontes, discos magnéticos, dispositivos de leitura e escrita, vídeo, teclado, mouse.

Ligação entre páginas de Internet.

É a primeira página de um site, ou seja, a página de entrada.

Computador que hospeda os conteúdos de um site.

(Hyper Text Markup Language) - linguagem para a criação e visualização das páginas de Internet.

( Hyper Text Transfer Protocol ) - protocolo usado para a transferência de dados na Internet.

Instituto Brasileiro de Análises Sociais e Econômicas

Instituto Brasileiro de Geografia e Estatística

Instituto Brasileiro de Opinião Pública e Estatística

Inclusão Digital

Índice de Desenvolvimento Humano

Capacidade de um sistema operacional ou programa de permitir interação num processo.

É um conglomerado de redes em escala mundial de milhões de computadores interligados que permite o acesso a informações e todo tipo de transferência de dados. Chamada também de rede ou 'a rede das redes'.

A uma rede interna (dentro de uma empresa ou residência) que tem um servidor web Internet e outras ferramentas de comunicação dá-se o nome de Intranet.

Internet Protocol - Protocolo de Interconexão

É o Instituto Nacional de Estatística da Itália.

Uma linguagem orientada a objetos, baseada em $\mathrm{C}++$, que permite que os desenvolvedores desenvolvam aplicativos independentes de plataformas.

Grupo de pesquisa - Jovens em Rede- Departamento de Educação da PUC - Rio

Tipo de ficheiro com formato de imagem

Local Area Network - Uma rede de comunicações que cobre pequenas áreas geográficas. 
LAN House

Level

Link

LINUX

Login ou Logon

Logoff

Megabyte

Midia

Mídia digital

Modem

Moodle

Mouse

Motherboard

MP3
Estabelecimento comercial que loca o uso de computadores para jogos virtuais de última geração. Os jogos, normalmente, de conteúdo violento, são disputados simultaneamente, em tempo real, por diversos participantes, cada qual controlando os movimentos de um personagem que confronta com outros.

Nível de desenvolvimento ou progresso de um personagem no game.

Ligação entre páginas de Internet ou imagens e textos.

Sistema operacional, multitarefa, para computadores pessoais ( $\underline{P C s})$ desenvolvido pelo finlânes Linus Torvalds, em 1991. Disponibilizado gratuitamente na Internet, passou a receber a colaboração de outros programadores, o que tem contribuído para seu aperfeiçoamento.

Fazer acesso a Internet ou a uma página.

Processo de encerramento de uma seção em uma rede de comunicação.

É uma unidade que permite medir a quantidade de informação. Um megabyte equivale a 1024 kilobytes.

Qualquer meio de comunicação utilizado para veicular mensagens de conteúdo promocional ou publicitário.

Qualquer meio de comunicação baseado em tecnologia digital

De modulador demodulador, é um dispositivo eletrônico que modula um sinal digital em uma onda analógica, pronta a ser transmitida pela linha telefônica, e que demodula um sinal analógico recebido e o reconverte para o formato digital original.

Modular object-oriented dynamic learning environment (Ambiente de aprendizagem dinâmica modular orientada a objetos.)

Periférico que controla os movimentos do cursor na tela do computador, permitindo a abertura de programas e de menus e a seleção e execução de diversas funções por meio de cliques.

Placa mãe. Placa de circuitos eletrônicos com os principais componentes do computador.

Formato de músicas e sons que circulam pela Internet e que podemos armazenar no computador. 
MSN

MUD

Multimídia

My Space

Navegação

Netiqueta

NCP

Nó

OCSE

Offline

Online

ONU

Orkut

PC

Peer-to-Peer

Phishing

Placa de vídeo off-board
MSN Messenger. Programa de computador no qual o usuário adiciona amigos a uma lista privada. Sucedido pelo Windows Live Messenger.

Mult User Domain é um sistema análogo ao do chat, no qual, porem, a interação é vinculada a um tema narrativo e à definição de papéis (também através da construção de um duplo sintético chamado avatar) pela parte dos participantes.

Conceito usado para designar a existência de imagens, sons, textos e animações em um programa.

É um serviço de rede social que utiliza a Internet para comunicação online através de uma rede interativa de fotos, blogs e perfis de usuário.

Visitar web sites da Internet e conhecer seus conteúdos.

Regras de comportamento na Internet.

Network Control Protocol - Protocolo de controle de redes

Cada um dos computadores conectados a uma rede.

Organização para a Cooperação e o Desenvolvimento Econômico. Criada no período pós-guerra com o objetivo de cooperação e coordenação do campo econômico entre as nações européias.

Desconectado da Internet.

Conectado à Internet.

Organização das Nações Unidas

Programa de rede social de relacionamentos (Google, EUA, 2004).

Personal Computer: computador pessoal, projetado para ser utilizado, de forma interativa, por uma pessoa de cada vez.

Do inglês: par-a-par, entre pares, é uma arquitetura de sistemas distribuídos caracterizada pela descentralização das funções na rede, onde cada nodo realiza tanto funções de servidor quanto de cliente.

$\mathrm{Na}$ Internet, o phishing (às vezes chamado de carding ou brand spoofing) é um golpe no qual o autor distribui e-mails com aspecto legítimo, aparentemente vindos de alguns dos mais importantes sites da Web, com a intenção de roubar informações particulares e obter acesso às contas bancárias ou aos serviços por assinatura da vítima.

Circuito controlador de vídeo encontra-se disposto em placa independente, dedicada a esta função, fora da placa mãe. 


\author{
PNAD \\ PNUD \\ Podcasting \\ Pop-ups \\ Protocolo \\ RAM \\ $\mathrm{RDH}$ \\ Rede Social \\ ROM \\ RPG
}

Second Life

Servidor

Software
Pesquisa Nacional por Amostra de Domicílios

Programa das Nações Unidas Para o Desenvolvimento

Forma de publicação de arquivos de mídia digital (áudio, vídeo, foto, PPS, etc...) pela Internet, através de um feed RSS, que permite aos utilizadores acompanhar a sua atualização.

Mensagens que surgem e desaparecem em janelas instantâneas

É o conjunto de regras que governam a operação de unidades funcionais de um sistema de comunicações e que deve ser seguido para que a comunicação seja estabelecida conforme o desejado (Camarão, 1994).

Random Access Memory: Memória RAM (memória de acesso aleatório). Este tipo de memória permite tanto a leitura como a gravação e a regravação de dados. No entanto, assim que elas deixam de ser alimentadas eletricamente, ou seja, quando é desligado acidentalmente ou não - o computador, a memória RAM perde todos os dados Armazenados.

Relatório do Desenvolvimento Humano

é uma das formas de representação dos relacionamentos afetivos ou profissionais dos seres entre si ou entre seus agrupamentos de interesses mútuos.

Memória Somente para Leitura, cujo conteúdo pode ser lido, mas não modificado. Contém as informações necessárias para fazer o computador entrar em operação assim que é ligado.

Role Playing Game. Jogo de interpretação de papéis. Surgiu nos EUA, em 1974.

Software desenvolvido pela empresa Linden Labs que simula alguns aspectos a vida real e social do ser humano em um ambiente virtual e tridimensional. Os usuários do software criam personagens para poder interagir com 0 ambiente virtual como se ele fosse um ambiente real, com pessoas, casas, carros etc.

Computador central, em uma rede, responsável pela administração e fornecimento de programas e informações aos demais computadores a ele conectados.

O conjunto de informação e instalação necessário para que o computador funcione como tal, desempenhando uma função, como por exemplo, um game. Correspondem aos dispositivos "não duros" do computador, os programas (cf. hardware). 
Site

Skype

SLOT

Smile

Spam

Spambot

Spyware

TCP

Tibia

TICs

Twitter

UNESCO

Upar

Upload
É o endereço das páginas de Internet.

Software que permite comunicação de voz pela Internet através de conexões sobre VolP (Voz sobre IP) e pode substituir a linha telefônica tradicional

(informática) conector em forma de soquete, fixado e ligado eletricamente a uma placa de circuito no qual se pode encaixar uma segunda placa, destinada a estabelecer a conexão elétrica entre os circuitos de ambas .

S.

É uma mensagem de e-mail não-solicitada. Do ponto de vista do remetente, o spam é uma forma de mala direta, muitas vezes enviada a uma lista obtida através de um spambot, ou a uma lista obtida por empresas especializadas em criar listas de distribuição de e-mail.Para o destinatário, normalmente se trata de lixo eletrônico.

programa projetado para coletar, ou "colher", endereços de e-mail na Internet para criar listas de envio de e-mail no sentido de enviar mensagens não solicitadas.

Programas espiões são tecnologias que auxiliam na coleta de informações sobre uma pessoa ou empresa sem seu conhecimento. Também conhecidos como spybots, os programas espiões são códigos inseridos no computador de uma pessoa para coletar secretamente informações sobre o usuário e enviá-las a anunciantes ou outras partes interessadas.

Transmission Control Protocol - Protocolo de Controle de Transmissão

Game alemão da empresa Cipsoft (1997). É um MMORPG em 2D (perspectiva isométrica) de aventura medieval.

Tecnologias da Informação e da Comunicação

Twitter é uma rede social e servidor para microblogging que permite aos usuários que enviem e leiam atualizações pessoais de outros contatos (em textos de até 140 caracteres) através da própria Web, por SMS e por softwares específicos

Organização das Nações Unidas para a educação, a ciência e a cultura

Apropriado do inglês "up" e transformado em verbo. Significa subir de level.

Enviar arquivos para ou servidor ou para outro computador. 
URL

Usuário

Vírus

VRML

WAN

Worm

Web

Weblog

Web 2.0

Wiki

Wikipédia

Wireless

WWW
Endereço de uma página de Internet.

Qualquer pessoa que utiliza a rede para navegar, baixar e postar conteúdos.

Programas que danificam informações de um computador.

( Virtual Reality Modeling Language ) - sistema que permite a visualização em três dimensões

(Rede Remota) Uma rede física de comunicações que cobre grandes distâncias geográficas. Normalmente, as WANs funcionam em velocidades mais baixas que as LANs.

vírus que se copia sozinho e não altera arquivos, mas permanece residente na memória ativa. Os worms utilizam partes de um sistema operacional que são automáticas e, normalmente, invisíveis para o usuário.

Abreviação de www. (world wide web).

Baseia-se num software chamado blogger, que permite transformar um site num diário digital, para o registro de relatos do cotidiano de seu proprietário.

Termo criado em 2004 pela empresa estadunidense O'Reilly Media para designar uma segunda geração de comunidades e serviços, tendo como conceito a "Web como plataforma", envolvendo wikis, aplicativos baseados em redes sociais e Tecnologia da Informação.

Os termos wiki (pronunciado /uíqui/ ou /víqui/) são utilizados para identificar um tipo específico de coleção de documentos em hipertexto ou o software colaborativo usado para criá-lo.

Enciclopédia multilíngue online livre colaborativa, ou seja, escrita internacionalmente por várias pessoas comuns de diversas regiões do mundo, todas elas voluntárias.

Tecnologia de conexão com a Internet através de ondas eletromagnéticas, dispensando o uso de fios e cabos. (wi-fi)

World wide web, conhecida como web, rede de alcance mundial que condensa informações de hipertexto (som, imagem, movimento), criada em 1992 por Tim Berners-Lee. 


\section{Lista de figuras}

Figura 1 - As tecnologias nas relações de trabalho ..................................... 43

Figura 2 - Inclusão pelo mouse ............................................................. 76

Figura 3 - Inclusão digital e construção da cidadania ................................ 128

Figura 4 - A inclusão é digital ou social? .............................................. 145

Figura 5 - Para aprender não tem idade .............................................. 169

Figura 6 - De LAN em LAN ........................................................... 177

Figura 7 - Fachada da sede matriz do CDI - Rio de Janeiro ...................... 188

Figura 8 - Modelo atual de classificação das LAN Houses no CNAE ......... 193

Figura 9 - Jovens do Projeto 'terza àrea' durante a aplicação do

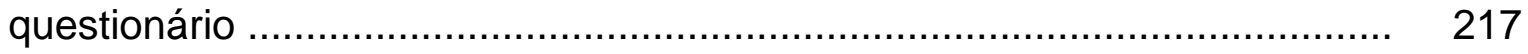




\section{Lista de gráficos}

Gráfico 1 - Diferença entre média de rendimentos entre países .................. 143

Gráfico 2 - Tráfego na Internet por dia de semana - agosto/set. 2009 ........ 147

Gráfico 3 - Acesso à Internet na Itália - 1997/ 2008 (número em milhares) . 163

Gráfico 4 - Percentual dos usuários italianos por faixa etária ...................... 164

Gráfico 5 - Percentuais da freqüência de uso da Internet por faixa etária .... 166

Gráfico 6 - Os dez mais ................................................................ 180

Gráfico 7 - A Internet como lugar para jovens brasileiros e italianos ........... 222

Gráfico 8 - Quando penso em Internet penso em.... para jovens brasileiros

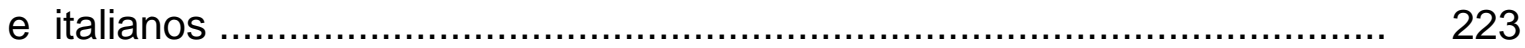




\section{Lista de quadros}

Quadro 1 - Distribuição das repostas dadas para a categoria relacional dos meios

Quadro 2 - Usos e apropriações na rede ............................................... 68

Quadro 3 - Trilhas metodológicas percorridas ..................................... 103

Quadro 4 - Resultados obtidos: usos .................................................. 224

Quadro 5 - Resultados obtidos: apropriações ..................................... 224 


\section{Lista de tabelas}

Tabela 1 - Estatística de Usuários de Internet e População no Mundo

Tabela 2 - Tempo de uso e acesso por pessoas, números de usuários ativos

Tabela 3 - Número de usuários e tempo de navegação

Tabela 4 - Internautas domiciliares ativos e horas navegadas ${ }^{\star \star}$ - 2009

Tabela 5 - Proporção de domicílios com computador - percentual sobre o total de domicílios

Tabela 6 - Local de acesso individual a Internet

Tabela 7 - Motivos para a falta da Internet no domicílio 156 